\title{
O DISCURSO DOS LIVROS DIDÁTICOS DE GEOGRAFIA: AS DIFERENÇAS ENTRE O PERÍODO MILITAR E A PRIMEIRA QUINZENA DO SÉCULO XXI
}

\author{
Mariana Xavier de Oliveira ${ }^{1}$ \\ Andre Zanki Cordenonsi ${ }^{2}$
}

Resumo: A presente pesquisa objetiva comparar o discurso e a apresentação dos conteúdos de geografia física dos livros didáticos de geografia utilizados nas escolas públicas do Brasil no Período Militar com os atuais, tomando como base o ano de 2014. Especificamente objetiva-se: analisar a distribuição dos conteúdos e capítulos referentes à geografia física presentes nos livros didáticos; e comparar como era e é realizada a redação destes conteúdos frente à linguagem utilizada. Para desenvolver a pesquisa foi adotada uma metodologia qualitativa, a partir da análise descritiva de livros didáticos e do conteúdo analisado dos referidos períodos, levando, desta maneira, à compreensão do tema proposto. Os livros didáticos escolhidos para a análise foram: AZEVEDO, Aroldo de. Terra brasileira. 42. ed. São Paulo: Companhia Editora Nacional, 196; e MARTINS, Dadá; BIGOTTO, Francisco; VITIELLO, Márcio. Geografia: Sociedade e cotidiano. 4. ed. São Paulo: Escala Educacional, 2012. Desta forma, conclui-se que: há diferenças e semelhanças entre os livros trabalhados. Apesar de claras diferenças de discurso, os dois cumprem seu papel como fornecedor de conhecimento e recurso de auxílio ao professor em sala de aula. Sendo assim, não se notou nenhum erro conceitual em nenhuma das obras, sugerindo assim, que ambas são indicadas para cumprir sua função. Desta forma, nota-se que diversos aspectos influenciam no discurso apresentado nos livros didáticos: como esperado, a questão política está mais explícita no livro didático do Período Militar que o do atual, já as questões voltadas à preservação do meio ambiente são mais evidentes no livro atual que no do ano 1968. Portanto, independente do período histórico $e$ do que se evidencia neste tempo, desenvolver $e$ preservar o criticidade dos educandos através da indagação do conteúdo presente em qualquer mídia é uma das inúmeras funções intrínseca a profissão de professor.

Palavras-chave: Livro Didático; Geografia Física; Período Militar; Atualidade.

\section{The speech of textbook of Geography : the differences between thw Period Military and the fortnight of the XXI century.}

Abstract: This research aims to compare the speech and the presentation of content from physical geography of geography textbooks used in public schools in Brazil during the military period with current, based on the calendar year 2014. Specifically aims to: analyze the distribution contents and chapters on physical geography present in textbooks; and compare how was the writing and the latter from the language used content is performed. To develop

1. Licenciada em Geografia UFSM, 2011; Mestre em Geografia, UFSM 2014; Especialista em Mídias na Educação, UAB/UFSM 2015; Doutoranda em Geografia, UFRGS (mxavieroliveira@gmail.com).

2. Doutor em informática, UFRGS. Professor adjunto da Universidade Federal de Santa Maria (andrezc@inf.ufsm.br). 
the research, a qualitative methodology was adopted from the descriptive analysis of textbooks and content analysis of these periods, leading in this way to understand the proposed theme. The textbooks chosen for analysis form: Azevedo, Aroldo of. Terra brasileira. 42 ed. São Paulo: Companhia Editora Nacional, 1968. and MARTINS, Dada; BIGOTTO, Francisco; VITIELLO, Márcio. Geografia: Sociedade e cotidiano. 4 Ed São Paulo: Educational Scale, 2012 Thus, one can conclude that one can realize that there are differences and similarities between the books worked. That despite clear differences in speech, every two fulfill their role as provider and knowledge resource to aid the teacher in the classroom. So not noticed any conceptual error in any of the works, thus suggesting that both are set to fulfill its role. Thus, we note that various aspects influence the discourse presented in textbooks: as expected the political issue is explicit in the textbook of the military that the current period, since the issues facing the preservation of the environment more evident in the current books that in the year 1968 So, regardless of the historical period and disclose that at this time, develop and preserve the criticality of learners through inquiry of what is broadcast in any media, is one of the many intrinsic functions the teaching profession.

Key words: Textbook; Physical Geography; Military Period; Current.

\section{INTRODUÇÃO}

A educação no Brasil tem sofrido muitas mudanças durante sua história. O livro didático, que foi criado com o intuito de ser um instrumento de auxílio ao professor na sala de aula e também de padronizar os conteúdos abordados em cada série, tem sido muitas vezes o meio mais tradicional usado pelos docentes em suas práticas escolares. Nesta busca de padronização de saberes, há tempos que o governo procura estabelecer parâmetros curriculares comuns em todo país, e assim tem encontrado nos livros didáticos um importante instrumento para alcançar este objetivo, uma vez que esses eram diferenciados nas variadas regiões do país (KUNZLER; WIZNIEWSKY, 2007).

Entender a história do processo de produção dos livros didáticos é fundamental para contribuir com o aprimoramento deste recurso, essencial para o funcionamento das escolas. Além disso, é possível neste processo, utilizar-se de diversificadas ações e mídias buscando integrá-las ao livro didático a fim de propor um estímulo maior aos educandos (ASSUNÇÃO, 2009).

O livro didático torna-se uma mídia necessária à prática docente nas diversas disciplinas escolares, por ser, muitas vezes, o único recurso presente na escola que ilustra ou complementa o assunto que está sendo abordado com os alunos. Além disso, o livro didático 
segundo Martins (2006, p. 1) "torna-se cada vez mais um elemento necessário ao complemento das atividades didático-pedagógicas realizadas em sala de aula, sendo utilizado, entre outros, como um meio auxiliar e facilitador da sua prática".

Uma vez que possua tal importância, é fundamental que o livro didático não vá contra a filosofia proposta pela escola, bem como atenda aos objetivos intrínsecos ao professor em sua proposta de ensino e, também, as características do grupo de estudantes e a realidade onde trabalha (MARTINS, 2006). Desta forma, percebe-se que hoje o livro didático tem muita importância no apoio à formação das crianças e adolescentes, contudo não se encontra estudos voltados ao discurso adotado nestes recursos ao longo da história, ainda mais durante o Período Militar, momento este que os militares administraram o país e buscaram instrumentalizar o ensino para a aplicação de seu projeto de Estado à sociedade brasileira.

Além disso, neste período, instituições de abrangência nacional passaram por diversas transformações para contemplar as ideias impostas pelos militares. Assim, pode-se perceber que a política centralizadora do Período Militar, segundo Kunzler e Wizniewsky (2007, p.198) "atacou em muitas frentes, e o livro didático, como o mais importante instrumento de ensino empregado nas salas de aula brasileiras [...] também fez parte do 'pacote' de mudanças que alicerçaram o período".

Desta forma, a presente pesquisa possui como objetivo geral comparar o discurso e a apresentação dos conteúdos de geografia física dos livros didáticos de geografia utilizados nas escolas públicas do Brasil no Período Militar com os atuais, tomando como base o ano calendário letivo de 2014. Especificamente objetiva-se: analisar a distribuição dos conteúdos e capítulos referentes à geografia física presentes nos livros didáticos e comparar como era e é realizada a redação destes conteúdos frente à linguagem utilizada.

Justifica-se este trabalho pela possibilidade de verificar a existência da imposição do discurso nacionalista nos livros do Período Militar e ambientalista nos livros do período atual, bem como verificar a evolução destes discursos com o passar dos anos. Sabe-se que a Ciência Geográfica sofre modificações diárias frente à dinâmica imposta por seu objeto de estudo que é o espaço geográfico, mas é sabido também que temas desta ciência são comuns ao ensino deste que ela estruturou-se para se tornar uma temática escolar. Sendo assim, não se 
busca aqui criticar a abordagem utilizada naquele período ou atualmente, mas, sim, fazer uma constatação sobre a mudança sofrida nestas mídias com a modificação política ideológica brasileira destes dois períodos.

\section{REFERENCIAL TEÓRICO}

\section{Breve histórico do Programa Nacional do Livro Didático (PNLD)}

O PNLD é um dos mais antigos programas voltados à distribuição de obras didáticas para a rede pública de ensino no Brasil. Ao longo do tempo, já deteve diversas denominações, e é assim conhecido desde 1985. Atualmente, este programa é voltado a atender a educação básica brasileira (FNDE, 2014).

Diante disso, diversos foram os decretos e leis que aperfeiçoaram este programa, que teve início em 1929, quando o Estado cria o Instituto Nacional do Livro (INL), a fim de legitimar o livro didático nacional e auxiliar a respeito do aumento da produção deste recurso. Posteriormente, em 30 de dezembro de 1938, o Decreto-Lei no 1006, estabelece as "condições de produção, importação e utilização do livro didático" no país, sendo a primeira lei brasileira que aborda a temática referente a este recurso. Além disso, esta lei passa a ditar quais serão as condições para a comercialização e utilização do livro didático nas salas de aula da educação básica no país (FNDE, 2014).

Este Decreto-Lei institui em seus nono e décimo artigos, a Comissão Nacional do Livro Didático (CNLD) e suas atribuições, onde,

Art. 9o Fica instituída, em caráter permanente, a Comissão Nacional do Livro Didático.

$\S 1$ 10 A Comissão Nacional do Livro Didático se comporá de sete membros, que exercerão a função por designação do Presidente da República, e serão escolhidos dentre pessoas de notório preparo pedagógico e reconhecido valor moral, das quais duas especializadas em metodologia das línguas, três especializadas em metodologia das ciências e duas especializadas em metodologia das técnicas.

$\S 2$ ㅇ Os membros da Comissão Nacional do Livro Didático não poderão ter nenhuma ligação de caráter comercial com qualquer casa editora do país ou do estrangeiro.

§ 3ㅇ Os membros da Comissão Nacional do Livro Didático perceberão, por sessão a que comparecerem, a diária de cem mil réis, limitado, porém, a um conto de réis, o máximo dessa vantagem em cada mês. Art. 10. Compete à Comissão Nacional do Livro Didático. 
a) Examinar os livros didáticos que the forem apresentados, e proferir julgamento favorável ou contrário à autorização de seu uso;

b) Estimular a produção e orientar a importação de livros didáticos;

c) Indicar os livros didáticos estrangeiros de notável valor, que mereçam ser traduzidos e editados pelos poderes públicos, bem como sugerir-lhes a abertura de concurso para a produção de determinadas espécies de livros didáticos de sensível necessidade e ainda não existentes no país;

d) Promover, periodicamente, a organização de exposições nacionais dos livros didáticos cujo uso tenha sido autorizado na forma desta lei. (BRASIL, Decreto-Lei no 1006, 30 dez. 1938).

Mas apesar das leis a respeito do livro estarem agindo para a melhora deste recurso, apenas em 26 de dezembro 1945, com o Decreto-Lei no 8460, que o professor pode escolher com que obra trabalhar. Este menciona que,

Art. 5o - Os poderes públicos não poderão determinar a obrigatoriedade de adoção de um só livro ou de certos e determinados livros para cada grau ou ramo de ensino nem estabelecer preferência entre os livros didáticos de uso autorizado, sendo livre aos professores de ensino primário, secundário, normal e profissional a escolha de livros para uso dos alunos, uma vez que constem da relação oficial das obras de uso autorizado.

Já em 1966, o Ministério da Educação (MEC) e United States Agency for International Development (USAID) acordaram em coordenar ações referentes à produção, edição e distribuição do livro didático no Brasil, com isso, o MEC garantiu recursos para a distribuição gratuita de 51 milhões de livros no período de três anos. Além disso, com a portaria no 35, de 11 de março de 1970, o MEC efetivou o sistema de co-edição de livros com as editoras nacionais com recursos do INL garantindo assim, continuidade do programa (FNDE, 2014).

Em 1971, o INL passa a desenvolver o Programa do Livro Didático para o Ensino Fundamental (PLiDEF), tomando para si as atribuições administrativas e de gerenciamento dos recursos financeiros referentes a este que, anteriormente eram a cargo da Comissão do Livro Técnico e Didático. Foi neste ano que se findou o convênio MEC/USAID, uma vez que houve a implantação do sistema de contribuição financeira das unidades federadas para o Fundo do Livro Didático (FNDE, 2014).

Através do Decreto no 77.107, de quatro de fevereiro de 1976, o governo troca a responsabilidade de edição e distribuição de livros textos, do INL, que se extingue, para a Fundação Nacional do Material Escolar (FENaME). Sendo assim, os recursos financeiros que eram destinados ao Programa de Colaboração Financeira para Edição de Livros Textos são 
transferidos para a FENaME, a quem passa a ter competência de movimentá-los, atendendo as diretrizes fixadas pelo Ministério da Educação e Cultura (BRASIL, Decreto no 77.107, de 04/02/1976).

Ainda no ano de 1976, devido à insuficiência de recursos para atender todos os estudantes do ensino fundamental da rede pública, a grande maioria das escolas municipais é excluída do programa (FNDE, 2014).

Em 1985, o presidente da república José Sarney implanta o Programa Nacional do Livro Didático (PNLD) com o Decreto no 91.542, de 19 de outubro de 1985, onde se institui,

Art. 19. Fica instituído o Programa Nacional do Livro Didático, com a finalidade de distribuir livros escolares aos estudantes matriculados nas escolas públicas de 10 Grau.

Art. 20. O Programa Nacional do Livro Didático será desenvolvido com a participação dos professores do ensino de 10 Grau, mediante análise e indicação dos títulos dos livros a serem adotados [...].

Art. 3․ Constitui requisito para o desenvolvimento do Programa, de que trata este Decreto, a adoção de livros reutilizáveis [...].

Art. 4․ A execução do Programa Nacional do Livro Didático competirá ao Ministério da Educação, através da Fundação de Assistência ao Estudante FAE, que deverá atuar em articulação com as Secretarias de Educação dos Estados, Distrito Federal e Territórios, e com órgãos municipais de ensino, além de associações comunitárias [...]

Art. 5․ A secretaria de Ensino de 10 e 20 Graus - SEPS, do Ministério da Educação, responderá pela formulação, supervisão e avaliação da Política do livro didático.

Art. 60. O Programa Nacional do Livro Didático instituído por este Decreto entrará em vigor no ano letivo de 1986.

No ano de 1986, o PLiDEF é incorporado a Fundação de Assistência Estudantil (FAE) em substituição a FENaME. Como consequência, este grupo passa a ser encarregado de detectar problemas relativos às obras didáticas e desta forma, passa a propor a participação dos docentes na escolha e produção dos livros a fim de ampliar o programa.

A distribuição dos livros é afetada pelas restrições orçamentárias no ano de 1992. Assim, o programa restringe o seu atendimento até a 4a série do ensino fundamental. Em conseguinte, já no ano de 1993, a Resolução CD FNDE no 6 vincula, em julho de 1993, recursos para a obtenção dos livros didáticos dedicados aos educandos das redes públicas de 
ensino, estabelecendo-se, assim, um fluxo regular de verbas para a obtenção e repartição do livro didático (FNDE, 2014).

Logo, a partir do ano de 1995, de forma gradativa, a distribuição do livro didático no ensino fundamental volta a abranger todos os anos escolares. Desta forma, em 1995, são consideradas as disciplinas de matemática e língua portuguesa, em 1996, a de ciências e, em 1997, as de geografia e história (FNDE, 2014).

Os Guias de Livros Didáticos de 1ạ a 4ạ série, surgem no ano de 1996 com o intuito de aperfeiçoar as obras, sendo publicados até hoje. Desta forma, todos os livros que apresentarem erros conceituais, indução a erros, desatualização, preconceito ou discriminação de qualquer tipo são excluídos do Guia do Livro Didático.

Em 1997 extingue-se a FAE, desta forma a responsabilidade pela política de execução do PNLD é transferida integralmente para o Fundo Nacional de Desenvolvimento da Educação (FNDE). Assim, o programa é ampliado e o Ministério da Educação passa a adquirir, de forma continuada, livros didáticos de alfabetização, língua portuguesa, matemática, ciências, estudos sociais, história e geografia para todos os alunos de $1^{\text {a }}$ a $8^{\underline{a}}$ série do ensino fundamental público (FNDE, 2014).

No ano 2000 o PNLD passa a distribuir dicionários da língua portuguesa para uso dos colegiais de 1a a 4a séries e em 2001 e, pela primeira vez na história do programa os livros didáticos passam a ser entregues no ano anterior ao ano letivo de sua utilização. Ainda em 2001, o PNLD amplia, de forma gradativa, o atendimento aos educandos portadores de deficiência visual que estão nas salas de aula do ensino regular das escolas públicas, com a distribuição do livro didático em braile (FNDE, 2014).

Em 2007 o FNDE adquire 110,2 milhões de livros para reposição e complementação de

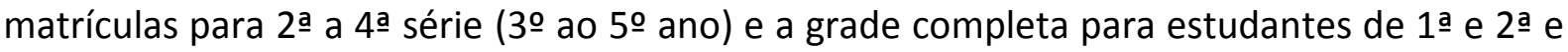

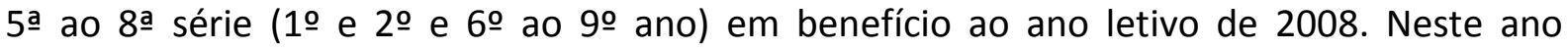
também adquire dicionários trilíngues (português, inglês e libras) para fornecer aos discentes com surdez das escolas de ensino fundamental e médio. Esses educandos, de 1a a 4a série, passar a receber também cartilhas e livros de língua portuguesa em libras e em CDrom (FNDE, 2014). 


\section{O Período Militar e suas políticas educacionais}

O regime militar no Brasil foi instaurado em primeiro de abril de 1964 com o golpe militar e durou até 15 de março de 1985 quando José Sarney assumiu a presidência, dando início ao período conhecido como Nova República.

Neste período, a Constituição de 1946 foi substituída pela Constituição de 1967, esta que foi a sexta do Brasil e a quinta da República. Tinha como objetivo institucionalizar e legalizar o regime militar, aumentando a influência do Poder Executivo sobre o Legislativo e Judiciário e criar desta forma, uma hierarquia constitucional centralizadora. As atribuições do Poder Legislativo, com o aval do Poder Executivo e Judiciário, passaram a ser únicas e exclusivas dos que exerciam o Poder Executivo, ficando os demais Poderes relevados à meros espectadores das aprovações dos "pacotes", como seriam posteriormente nominadas as emendas e legislações baixadas pelo Presidente da República (WIKIPÉDIA, 2014).

Além disso, o Congresso Nacional foi dissipado, liberdades civis foram extintas e foi criado um código de processo penal militar que permitia que o Exército Brasileiro e a Polícia Militar do Brasil pudessem prender e encarcerar pessoas consideradas suspeitas, além de impossibilitar qualquer revisão judicial (WIKIPÉDIA, 2014).

O novo regime adotou uma diretriz nacionalista, desenvolvimentista e de oposição ao comunismo. A ditadura atingiu o auge de sua popularidade na década de 1970, com o "milagre brasileiro" ${ }^{3}$.

No entanto na década de 1980, a ditadura brasileira entrou em decadência quando o governo não conseguiu mais estimular a economia, controlar a inflação e os níveis crescentes de concentração de renda e de pobreza provenientes de seu projeto econômico, o que possibilitou então o surgimento e ascensão do movimento pró-democracia. Assim, o governo aprovou a Lei de Anistia para os crimes políticos cometidos pelo e contra o regime,

3. O período 1968-1973 é conhecido como "milagre" econômico brasileiro, em função das extraordinárias taxas de crescimento do Produto Interno Bruto (PIB) então verificadas, de 11,1\% ao ano. Uma característica notável do "milagre" é que o rápido crescimento veio acompanhado de inflação declinante e relativamente baixa para os padrões brasileiros, além de superávits no balanço de pagamentos (Veloso; Villela; Giambiagi, 2008, p. 221). 
as restrições às liberdades civis foram relaxadas e, desta forma, em $1984^{4}$, pode-se realizar eleições presidenciais com candidatos civis.

Tratando-se de ensino, todos os níveis deste sofreram alterações durante o Período Militar, algumas dessas são visíveis até hoje no sistema educacional vigente. O estado passou a editar políticas que buscavam o tecnicismo do ensino nas escolas públicas de 10 e 2 으 grau, mesmo comprometendo a sua qualidade. Houve também o controle das atividades acadêmicas nas universidades e a expansão das instituições universitárias particulares (FERREIRA JR E BITTAR, 2006).

Assim, a passagem da década de 1960 para a de 1970 foi marcada por mudanças estruturais no sistema educacional nacional. Desta forma, houve o estabelecimento de vínculos entre a educação e o modelo autoritário de modernização das relações capitalistas de produção. Desta forma, Médici (1971) salientava que a revolução educacional passaria a surgir com a preparação dos educandos com o ensino técnico o que revolucionaria o desenvolvimento do país.

Para tender essa mudança, realizaram-se duas grandes reformas jurídicas no campo do ensino. A primeira foi a Lei n. 5.540, de 28 de novembro de 1968, que reorganizou o funcionamento do ensino superior e sua articulação com a escola média; e a segunda foi a Lei n. 5.692, de 11 de agosto de 1971, que reestruturou os antigos primário e ginásio, criando o ensino de 1 을 2 을 graus $^{5}$ (FERREIRA JR E BITTAR, 2006).

\section{O livro didático de geografia}

Enquanto disciplina escolar, a Geografia está institucionalizada no Brasil desde o início do século XIX. Presentemente a Geografia é disciplina escolar por doze anos. Durante esse tempo, a cada ano, novos conteúdos são expostos e difundidos pelos professores a partir e por meio dos livros didáticos (PINNA, 2009).

4. Esta foi a última eleição brasileira ocorrida de forma indireta, através de um Colégio Eleitoral, sob a égide da Constituição de 1967. Disputavam a sucessão do Presidente João Figueiredo, as seguintes chapas: Aliança Democrática: Tancredo de Almeida Neves/José Sarney e Partido Democrático Social: Paulo Salim Maluf/Flávio Portela Marcílio (WIKIPÉDIA, 2014).

5. Da junção dos quatro anos do ensino primário com os quatro do ginásio foi criado um único ciclo de oito anos, o chamado 10 grau de ensino, que passou a ser obrigatório. Quanto aos três anos do antigo ensino colegial, passaram a constituir o $2 \stackrel{\circ}{\mathrm{g}}$ rau. 
Um dos materiais didáticos mais utilizados para o desenvolvimento da disciplina de Geografia na escola é o livro didático, em muitos casos este recurso foi e é o orientador das aulas, restringindo o conhecimento a tal recurso. A necessidade se dá, uma vez que o objeto de estudo desta ciência é o espaço geográfico e há necessidade de demonstrá-lo por meio de imagens, essas muitas vezes retratadas nestes livros.

Sabe-se e reconhece-se que o material didático mais popular e acessível pelos educandos e professores é o livro, uma vez que existem várias políticas ligadas a sua produção e difusão pelas escolas públicas do país. Nota-se que, muitas vezes, esse é o único recurso utilizado em sala de aula, sendo um meio até de atualização do professor acerca de conteúdos mais dinâmicos.

Percebe-se também que várias são as críticas levantadas às relações de ensino e aprendizagem direcionadas à utilização restrita do livro didático na escola, uma vez que conteúdos como as ciências, a história e claro, a geografia oferecem vivências mais práticas para os estudantes, essas que muitas vezes não são apresentadas nem estimuladas nos livros didáticos. Além disso, muitos livros são tendenciosos a respeito de seu discurso e nem sempre são imparciais em suas preferências pedagógicas e políticas.

Nesse sentido, observando a importância e o papel que os livros didáticos têm na sala de aula, uma análise do discurso apresentado por ele, mais precisamente quando se trata da parte da Geografia atribuído as ciências humanas, é essencial. Sendo assim, cabe ao professor ter conhecimento da contrapartida do que é apresentado, para que os discentes possam conhecer as partes envolvidas e posicionar-se a respeito do tema.

Sabe-se que por muito tempo, os autores dos livros didáticos não preocupavam-se em ser ou parecer neutos nas preferências políticas empregadas e difundidas nos livros didáticos, e também se sabe hoje essas preferências aparecem sutilmente nos discursos didáticos. Desta forma, é necessário que o professor possa e saiba se posicionar e argumentar a respeito de determinados temas, para não impor aos discentes a sua preferência política pessoal, orientando-os a pensar sobre o que é melhor para os interesses de seu país e melhor para a população que nele vive. 
Como consequência, este artigo vem apresentar dois períodos históricos distintos, onde as políticas envoltas a formação do discurso apresentado nos livros didáticos são diferenciados, afim de que se possa refletir sobre como evoluiu-se ou não a respeito do que apresenta-se aos colegiais atualmente, e o que era disseminado há quase 50 anos atrás.

\section{METODOLOGIA}

Para desenvolver a pesquisa, foi adotada uma metodologia qualitativa, a partir da análise descritiva de livros didáticos e do conteúdo analisado dos referidos períodos, levando, desta maneira, à compreensão do tema proposto. Os livros analisados são de autores expressivos do Período Militar e do atual, sendo esses, referências de literaturas dentro da ciência geográfica.

O livro do Período Militar é uma das obras que faz parte da leva de livros disponibilizados às escolas de acordo com o tratado assinado em janeiro de $1967^{6}$, já o do período atual é um livro dos que hoje são distribuídos pelo PNLD.

\section{MATERIAIS E MÉTODO}

Os livros didáticos escolhidos para a análise formam: AZEVEDO, Aroldo de. Terra brasileira. 42. ed. São Paulo: Companhia Editora Nacional, 1968 e MARTINS, Dadá; BIGOTTO, Francisco; VITIELLO, Márcio. Geografia: Sociedade e cotidiano. 4. Ed. São Paulo: Escala Educacional, 2012 (Figura 1).

No livro Terra Brasileira apenas a primeira parte foi analisada, pois ela apresenta a parte que trata da geografia física do Brasil, já do livro Geografia: sociedade e cotidiano, o capítulo abordado será o de número quatro.

6. O tratado assinado em seis de janeiro de 1967 profere que no prazo de três anos a contar daquele ano seriam colocados 51 milhões de livros didáticos nas escolas públicas brasileiras, sendo que ao MEC e ao SNEL seriam dadas as responsabilidades de execução deste plano e aos técnicos do USAID todo o controles desde a fabricação até "elaboração, ilustração, editoração e distribuição de livros, além da orientação das editoras brasileiras no processo de compra de direitos autorais de editores não-brasileiros, vale dizer, americanos" (ROMANELLI, 1997, p. 213). 
A partir da análise dos livros selecionados, foi possível traçar uma linha-padrão de apresentação e abordagem da geografia e, mais precisamente, do tema geografia física do Brasil, onde buscou-se identificar as diferenças de discurso na apresentação dos temas.

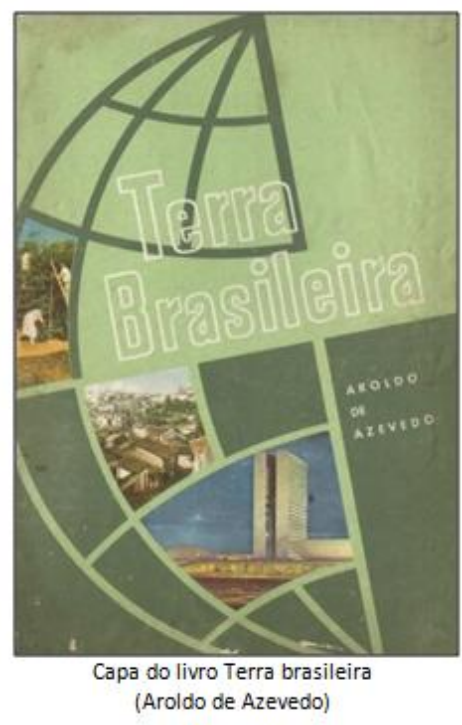

Figura 1: Capas dos livros didáticos analisados nesta pesquisa. Fonte: Oliveira, Mariana Xavier de (2015).

\section{RESULTADOS E DISCUSSÃO}

Tratando-se de discurso, diversas são as ressalvas que podem ser feitas nos livros didáticos. Na geografia, essa observação se confere no momento em que muitas temáticas geográficas dependem da política ora para se conceber, ora para se explicar.

Temas como definição de fronteiras, economia, migrações, população entre outras, são exemplificadas e entendidas pelo momento político passado por determinado Estado. Sendo assim, o entendimento deste momento explica claramente como busca se dar a formação educacional básica de um país.

Desta forma, observa-se claramente a diferença de discurso desses dois períodos distintos da história do Brasil, diferenças essas que serão relatadas nestes resultados.

\subsection{O discurso do livro didático de geografia do Período Militar}

O livro Terra Brasileira, tem seus conteúdos distribuídos em três grandes temas: 1) Nossa Terra, 2) Nossa Gente e 3) Nossa Economia. Nesses, o autor aborda aspectos distintos da Geografia do Brasil. No tema Nossa Terra o assunto tratado é geografia física, sendo dividido 
em seis capítulos: 1) O Brasil, país do futuro; 2) Terra de planaltos e planícies; 3) País atlântico; 4) País tropical; 5) Paraíso dos rios; e 6) Terra de florestas e campos, esses analisados neste artigo. No capítulo Nossa Gente o tema é geografia da população e no Grupo Nossa Economia, como o nome já anuncia, trata-se da geografia econômica.

No primeiro capítulo, "O Brasil, país do futuro", é apresentado o país em sua dimensão, suas fronteiras, sua posição geográfica, clima, vegetação, pontos extremos entre outros.

O título do capítulo se explica quando o autor afirma que "o Brasil é ainda muito jovem como nação organizada. Um país do futuro." (Azevedo, 1968, p. 19). O autor também ressalta que o povo esta em plena formação étnica quando expõe que

A maioria descende de europeus, de cor branca; mas nem todos tem a mesma origem; uns vieram da Europa atlanto-mediterrânea, outros procedem da Europa centro-oriental. A seu lado vive um número avultado de mestiços, que difere entre si: caboclos, mulatos, cafuzos. Possuímos milhões de negros, de origem africana, mas oriundos de áreas diferentes da África. Aqui vivem milhares de amarelos, embora uns sejam asiáticos, outros indígenas (Azevedo, p. 191, 1968).

O livro salienta que, apesar destas inúmeras etnias vivendo em um mesmo território "não existe ódios a separar uns dos outros", todos vivem em harmonia, como irmãos, falando uma só língua e seguindo a religião católica (AZEVEDO, 1968). Apesar disso, Azevedo (1968, p. 19-20) reconhece-se que o país vive grandes contrastes econômicos.

[...] grandes cidades, movimentadas e modernas, duas delas com mais de três milhões de habitantes, ao lado de um número muito maior de cidades médias e pequenas, de vilas e povoados. Áreas industriais, repletas de fábricas e de operários situadas a poucos quilômetros de fazendas e sítios, destinados à cultura ou criação, conhecendo a técnica moderna ou permanecendo dentro de sistemas antiquados. Regiões em pleno desenvolvimento econômico, não muito longe de regiões subdesenvolvidas. Enfim: o luxo de alguns, a vida dura e difícil para a maioria, a miséria para muitos.

Nota-se também no discurso, a necessidade de salientar que estas diferenças do país não devem ser valorizadas. Diante disso, o autor afirma que o Brasil ainda esta a se desenvolver, logo as diferenças presentes no país serão superadas pelas possibilidades intrínsecas ao território pouco explorado, extenso e com diferenças climáticas e pedológicas. Além disso, reafirma que outras diferenças precisam ser evitadas, como se observa na Figura 2. 
O Brasil é um país do futuro. O que precisa ser evitado é o desequilíbrio que traz a discórdia entre irmãos, as diferenças que podem gerar ódios.

Valorizando o patrimônio territorial que herdamos e garantindo a sobrevivência da civilização que recebemos de nossos antepassados, poderemos resolver tais problemas. Unidos, conseguiremos realizar o grande destino que nos espera.

Figura 2: Trecho do discurso do livro "Terra Brasileira". Fonte: AZEVEDO (1968).

Tratando-se especificamente da parte física do território, o capítulo dois apresenta um conteúdo bastante descritivo acerca da formação geológica do Brasil. O autor discorre sobre relevos modestos, quando se trata das baixas altitudes, o vasto planalto brasileiro, como a mais extensa e importante unidade de relevo e também as grandes planícies, tendo como exemplo a planície amazônica, o pantanal e as planícies costeiras.

O vasto litoral brasileiro é abordado no capítulo três: País Atlântico, onde o Azevedo (1968, p. 31) afirma que,

Com um litoral sem golfos profundos nem penínsulas salientes, o Brasil vêse banhado de águas do Oceano Atlântico numa extensão de cerca de 6000 $\mathrm{km}$.

Mas não é só por isso que é um país atlântico. Seu clima, em grande parte, sofre influências do grande oceano. Através das águas atlânticas recebemos no passado, os povoadores portugueses e africanos, que, ao lado dos indígenas, passaram a construir as bases de nossa nacionalidade. Pelas mesmas vias marítimas, em época mais recente, chegaram os imigrantes europeus e asiáticos, que vieram completar a formação do povo brasileiro.

Além disso, neste capítulo do livro o autor descreve o relevo submarino do oceano Atlântico, bem como suas influências no clima do Brasil, na salinidade das águas e na intensidade das marés. Também há apresentação das duas correntes marítimas que passam próximas ao litoral do país.

A formação de diferentes tipos de costas é explicada pela ação das águas oceânicas em contato com rochas e relevos diferentes. Para isso, Azevedo (1968, p. 35, - 36) explica que,

Umas são costas de abrasão, resultado da erosão marinha, geralmente altas e escarpadas: formam os costões que correspondem a belos exemplos de 
falésias e são típicos do litoral meridional [...]. Outras são costas de acumulação, resultantes da ação construtiva do Atlântico, em combinação com a acumulação de aluviões trazidos pelos rios [...] incluídas entre as mais belas do mundo.

O clima é abordado no capítulo quatro: País Tropical. Ele é apresentando salientando as diferenças em relação a vastidão continental do país, que permite que se tenha grandes diferenças climáticas entre o norte e o sul. Desta forma, Azevedo (1968, p. 41) afirma que "as chuvas, que predominam nos meses de verão, são mais ou menos abundantes na maior parte do nosso território; mas no sertão do nordeste recebe poucas chuvas e vê-se flagelado por terríveis períodos de seca".

Questões como temperaturas médias, média de chuvas, tipos de clima são descritos e ilustrados por mapas individuais (Figura 3).

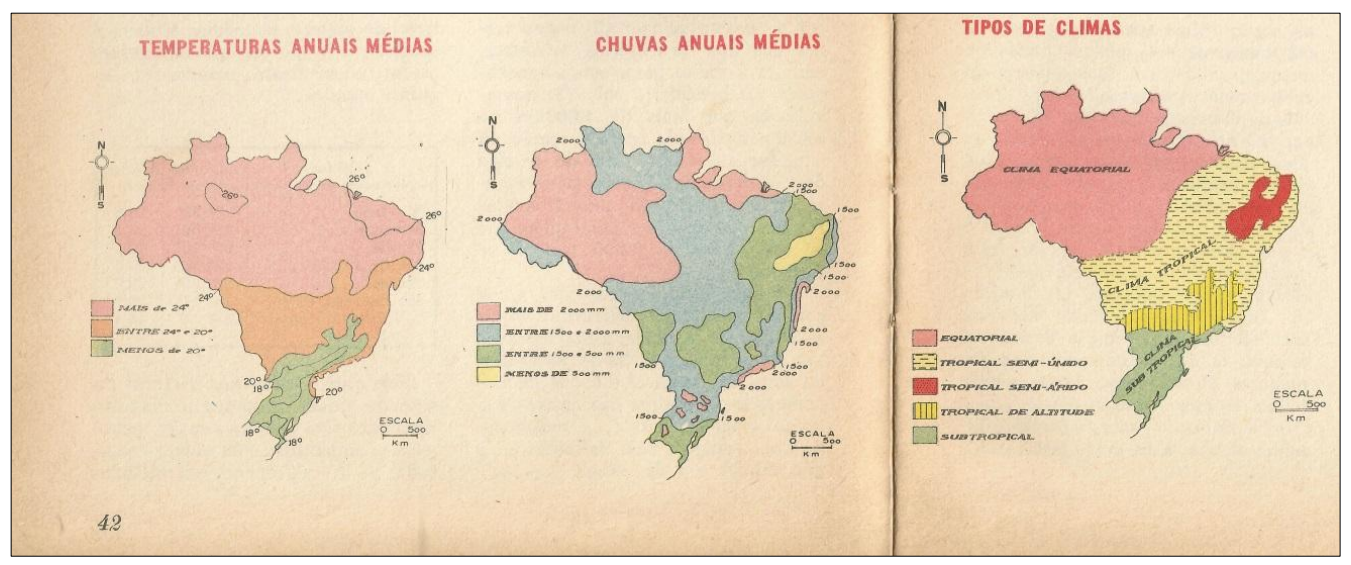

Figura 3: Cartografia do livro "Terra Brasileira". Fonte: AZEVEDO (1968)

O capítulo cinco, é o que trata da hidrografia do Brasil, intitula-se "Paraíso dos rios". Ele principia com o item: "Uma possante rede hidrográfica". Neste, além da descrição das principais bacias hidrográficas do país e do regime dos rios, destaca-se um trecho que retrata as características dos rios brasileiros e suas potencialidades.

$\mathrm{Na}$ vasta extensão do território brasileiro encontram-se rios de todos os tamanhos, alguns dos maiores do mundo, ao lado de pequeninos cursos d'água, regatos e ribeirões. De certa maneira, o Brasil pode ser considerado o paraíso dos rios. Entretanto, não representam os rios brasileiros papel de destaque como vias de transporte. E muitos fatores podem explicar este aparente absurdo: uns criados pelo próprio homem - o povoamento e as atividades econômicas; outros criados pela natureza - os terrenos geológicos, o relevo e o clima. [...] Mas a situação poderá modificar-se completamente. Canais fluviais destinado a contornar as quedas-d'água e a ligar as bacias entre si; represas e um sistema de comportas, capazes de 
regularizar a descarga fluvial; o povoamento e o desenvolvimento econômico das áreas mais afastadas - tudo isso poderá ser realizado pelo homem brasileiro. (Azevedo, 1968, p. 47).

A imensidão dos recursos hídricos brasileiros é tida como um orgulho nacional, frente às potencialidades que eles apresentam em sua vastidão.

O último capítulo a tratar sobre geografia física é o seis, que se intitula "Terra de Florestas e de Campos". Assim, as diferentes florestas brasileiras são descritas em sua extensão, formação vegetal e localização geográfica ao longo do território. O mesmo acontece com as caatingas, cerrados e campos. Exemplificando, a respeito dos campos Azevedo (1968, p. 57) explicita que,

Quando as árvores cedem lugar à vegetação rasteira, temos os verdadeiros campos, muitas vezes designados pelo nome campos gerais. Fazem lembrar as pradarias da América do Norte, os pampas da Argentina e as estepes da Europa e da Ásia. Aparecem no sudoeste do Rio Grande do Sul [...] São os tipos de solos, mais do que o clima, que parecem explicar sua presença.

Sobre a fauna brasileira, estas são apresentadas por não se destacar nem pelo tamanho, nem mesmo pela ferocidade em comparação com outras áreas também tropicais. Os peixes também são tidos como não volumosos por não terem condições vantajosas de concentração e nossas águas frias (AZEVEDO, 1968).

Concluindo as observações referentes aos livros didáticos do Período Militar do Brasil, notase que neste período a questão da supervalorização do país é apresentada de forma explicita em todos os conteúdos, bem como a comparação do Brasil com nações desenvolvidas mesmo que em aspectos mais físicos do que humanos. Além disso, não se percebe nenhuma investidura de discurso voltada para a preservação ambiental neste período, proporcionando o entendimento que neste tempo, essa não era uma preocupação latente.

\section{O discurso dos livros didáticos de geografia da primeira quinzena do século XXI}

O livro Geografia: sociedade e cotidiano tem seus conteúdos distribuídos em 12 capítulos: 1) Formação territorial do Brasil; 2) Regionalização do espaço brasileiro; 3) Regiões geoeconômicas; 4) Domínios naturais do Brasil; 5) População brasileira; 6) Movimentos populacionais; 7) Organização do espaço rural; 8) Urbanização brasileira; 9) Meio urbano: características sociais e ambientais; 10) Recursos minerais e fontes de energia; 11) Industrialização brasileira e 12) Transportes e meios de comunicação. 
O capítulo quatro, analisado aqui, inicia-se com a descrição feita por Warrem Dean, em 1990 quando sobrevoava o território brasileiro. Ele descreve características físicas da ocupação do espaço geográfico, destacando as irregularidades da paisagem como a cor dos pastos, a presença da floresta e as transformações ocorridas como a implantação de pastagens, estradas e cidades.

Assim, é possível perceber que a caracterização do espaço geográfico não se produz isoladamente, mas em conjunto com os componentes que a formam. No entanto, para estudos, diversos autores afirmam que a separação dos conteúdos facilita seu entendimento. Desta forma, percebe-se que os componentes que formam o espaço físico são abordados de forma distinta neste livro.

O relevo é o primeiro item descrito pelos autores. Esses explicam como as cores representam as altitudes no mapa (Figura 4), além de salientar onde se encontram os mais altos pontos do país.

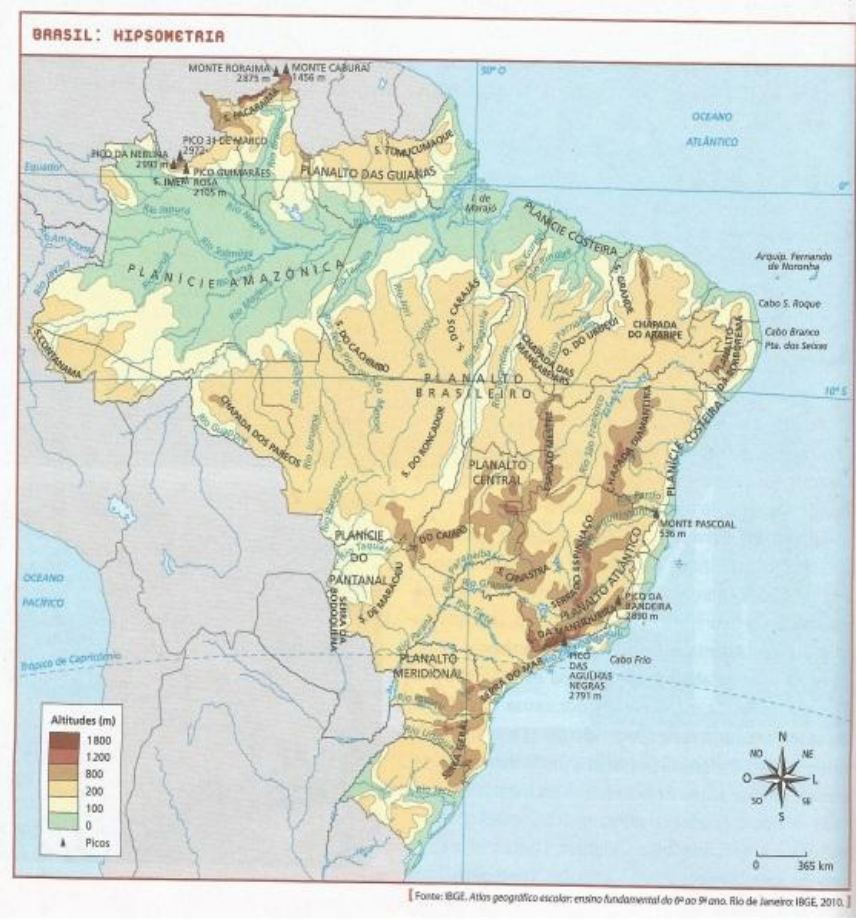

Figura 4: Cartografia do livro "Geografia: sociedade e cotidiano". Fonte: MARTINS; BIGOTO; VITIELLO (2012).

A questão de não haver grandes altitudes no Brasil, também é tratada e justificada em grande parte pela estrutura rochosa antiga e aos terrenos fortemente desgastados pela erosão (MARTINS; BIGOTO; VITIELLO, 2012). Além disso, o livro exemplifica diferentes 
formas de classificação do relevo brasileiro apresentado por autores, como Aroldo de Azevedo, Aziz Ab’Saber e Jurandyr Ross.

O assunto seguinte é a hidrografia brasileira, apresentada como sendo composta por uma extensa rede de drenagem. Os autores identificam as mais importantes bacias de drenagem do país e descrevem suas características bem como apresentam suas potencialidades, e também citam a presença de bacias secundárias.

A respeito de uma dessas bacias, Martins; Bigoto; Vitiello (2012, p. 72), citam que

O São Francisco, principal dessa bacia, nasce no sul de Minas Gerais, correndo mais de 3000 quilômetros até desaguar no Oceano Atlântico, na divisa entre os estados de Sergipe e Alagoas. [...]

O São Francisco é muito importante para a economia da região que atravessa, servindo de via de transporte, para irrigação, abastecimento e geração de energia elétrica. [...]

Nos últimos anos um amplo debate sobre a transposição de suas águas para irrigar áreas mais secas no Sertão, cujas obras já foram iniciadas, tem causado muita polêmica. Para alguns, antes de ampliar o seu uso, seria necessário recuperar o rio do forte processo de degradação que está submetido.

Pode-se perceber que há uma preocupação na manutenção desses mananciais, uma vez que o seu mau uso pode comprometer uma região inteira.

Tratando-se da temática clima, este é abordado de uma forma mais discreta. Martins; Bigoto; Vitiello (2012, p. 74) afirmam que "podemos identificar no território brasileiro os climas: equatorial, tropical úmido, tropical semiúmido, tropical de altitude, semiárido e subtropical". Assim, os autores descrevem cada um desses climas, pontuam suas regiões de ocorrência e apresentam dados relativos à precipitação somente.

Já em relação a vegetação, esta é abordada de forma ampla, uma vez que neste capítulo apresentam-se também as ocorrências de devastação ocorridas nestas. Desta forma, Martins; Bigoto; Vitiello (2012) apresentam as formações vegetais e salientam que elas encontram-se bastante alteradas pelas atividades humanas.

As principais formações arbóreas do país são abordadas, sendo elas caracterizadas, localizadas no território brasileiro e pontuadas as políticas que estão promovendo a sua 
manutenção e/ou as principais ameaças a sua continuidade. Como exemplo, Martins; Bigoto; Vitiello (2012, p. 75) afirmam que,

As regiões serranas do sul do país apresentam a formação florestal influenciada pelo clima subtropical: são as matas dos pinhais e de araucárias.

Nessa mata, a árvore predominante é a araucária ou pinheiro-do-paraná, que atinge até 40 metros de altura. A mata de araucária também tem sido muito explorada economicamente. Apesar dos esforços em conter o desmatamento, hoje restam apenas $10 \%$ da área original.

Os domínios morfoclimáticos são apresentados com uma indagação: "Como você agruparia um conjunto de características naturais (clima, relevo, vegetação)? Que relações esses elementos possuem entre si?". Aziz Ab'Saber responde está pergunta afirmando que "as paisagens são fruto de uma evolução integrada e complexa, participando de sua constituição uma estrutura rochosa, solos, coberturas vegetais e uma fisionomia específica, relacionada com a dinâmica climática e ecológica." (MARTINS; BIGOTO; VITIELLO, 2012, p. 79). Desta forma, Martins; Bigoto; Vitiello (2012, p. 75) denominam domínio morfoclimático como "uma área de uma paisagem natural, com características semelhantes de solo, hidrografia, vegetação, climas de relevo e clima".

Neste sentido, o livro afirma que o Brasil possui seis grandes domínios morfoclimáticos: amazônico, cerrado, mares de morros, caatinga, araucárias e as pradarias. Mas apesar de haver áreas com características típicas desses domínios, todos eles sofrem com os impactos ambientais em relação a sua devastação. Martins; Bigoto; Vitiello (2012, p. 83), afirma que,

Hoje, ao viajarmos pelo país, em regiões onde esperávamos encontrar cerrado, vemos grandes lavouras de soja; no pantanal, em vez de formações vegetais nativas, encontramos extensas pastagens; e, na região do domínio da mata atlântica, o que mais se vê são áreas agrícolas ou urbanizadas.

Esses problemas são atribuídos a diversos fatores, muitos deles ligados a "modelos de desenvolvimento econômicos descomprometidos com questões sociais e ambientais." (MARTINS; BIGOTO; VITIELLO, 2012, p. 84). Assim, Martins; Bigoto; Vitiello (2012, p. 85) afirmam que,

Se de um lado a revolução agrícola foi capaz de produzir grandes safras, por intermédia da modernização dos meios de produção, de outro proporcionou enormes danos ambientais e não resolveu o problema da distribuição equilibrada de alimentos no país. [...] 
A concentração de terras nas mãos de poucos, a prioridade às monoculturas de exportação, a ineficiência de alguns programas do governo e a má distribuição de renda vêm deixando muitas pessoas sem alimentos suficientes. Ampliar a reforma agrária e fornecer técnicas e subsídios à áreas rurais menos favorecidas são apenas uma etapa para reverter esse quadro.

Mas além de exemplificar os impactos ambientais, a presente obra também aborda as ações de preservação ambiental, afirmando que para que elas existam são necessárias ações e adoção de políticas educativas e públicas eficazes (MARTINS; BIGOTO; VITIELLO, 2012). Assim, há uma apresentação do código florestal e a instituição (imposta por ele) das Áreas de Preservação Permanentes e das Reservas Legais. Desta forma, essas áreas são conceituadas, segundo Martins; Bigoto; Vitiello (2012, p. 85 - 86)

As áreas de preservação permanente incluem topos de morros, nascentes, margens de rios e lagos, encostas com grande declividade entre outras. Já sobre a reserva legal, a lei estabelece que toda a propriedade rural deve conter uma área destinada à conservação da biodiversidade e a proteção de fauna e flora nativa.

Além disso, o livro já expõem algumas das novas resoluções imposta pelo novo código florestal brasileiro, aprovado em 2011. Porém mostra que há inúmeras críticas em relação a ele, por ser considerado menos restritivo que o primeiro (1960), podendo assim amparar por lei a possibilidade de exploração ambiental mais predatória que aumente os seus impactos negativos no meio ambiente.

As ilustrações a respeito da temática explicam e pontuam onde ocorrem essas áreas de preservação (Figura 5).
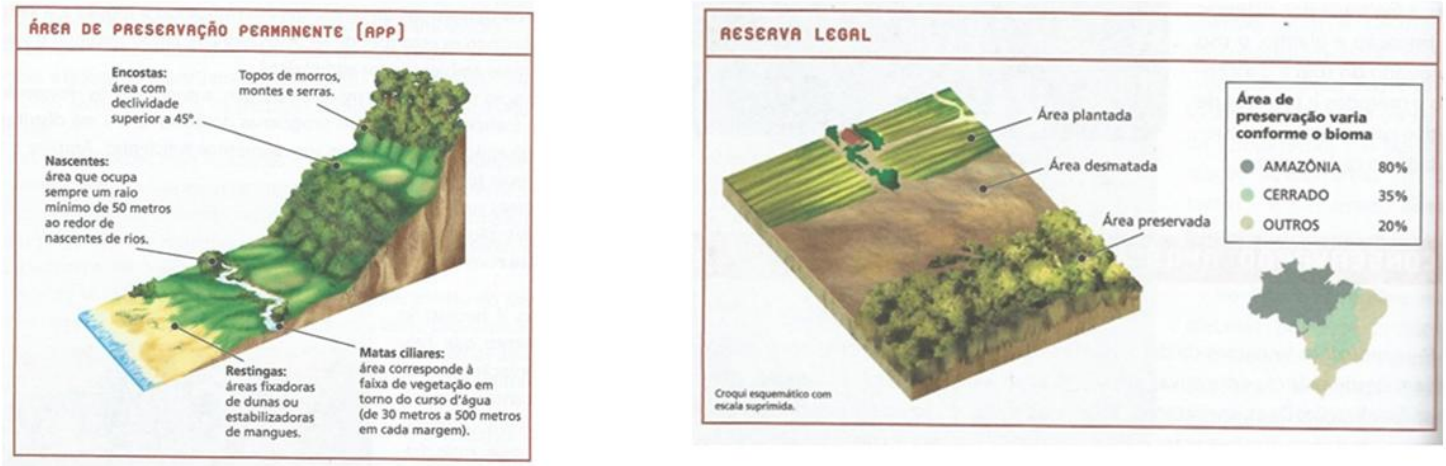

Figura 5: Ilustrações do livro "Geografia: sociedade e cotidiano" Fonte: MARTINS; BIGOTO; VITIELLO (2012). 
Além dessas, as unidades de preservação ambientais, amparadas por lei, também são apresentadas como prevendo a conservação dos ambientes naturais.

Finalizando a apresentação deste livro, percebe-se a diferença latente em relação à obra do Período Militar: o discurso voltado à preservação ambiental e não ao nacionalismo exagerado. Percebe-se que em nenhum momento o presente texto afirma que o Brasil é melhor que outra nação ou que precisa ou não adaptar-se para tornar-se um Estado desenvolvido. Ao contrário, mostra uma preocupação com os recursos naturais, muito afetados pela ação humana e quase sem nenhuma investidura pública eficaz para preservação e manutenção das áreas que ainda restam.

\section{CONCLUSÃO}

O resultado do artigo que aqui se apresenta constitui-se em um exercício intelectual embasado em um posicionamento pessoal específico, e por isso passível de diferentes interpretações. Desta forma, algumas considerações são necessárias.

Deve-se levar em conta os momentos históricos distintos apresentados nessa análise, e desta forma, considerar as distintas qualidades cartográficas apresentadas, bem como a ausência de determinados conteúdos do livro do Período Militar.

Tratando-se da apresentação do livro, eles se parecem bastante quando a forma de exposição, trabalhando primeiramente com os aspectos físicos, depois humanos e finalizando com os econômicos. Isso pode indicar que a complexidade e a inter-relação dos conteúdos são apresentadas de maneira gradativa, uma vez que a população de estabelece no meio físico e a questão econômica dependem das relações desses dois aspectos.

Tratando da geografia física, percebe-se que a temática se repete nos dois períodos históricos, recebendo a mesma abordagem, de trabalhar os conteúdos relacionados de forma separada. Essa metodologia é dita melhor para o entendimento dos educando acerca das temáticas tratadas.

No entanto, o livro de 2012, já mostra uma relação dos conteúdos sendo abordada, com a apresentação dos domínios morfoclimáticos do Brasil, indicando que aspectos como a 
regionalização podem e devem ser tratados mesmo quando os exemplos forem os fatores físicos do meio ambiente.

No livro de 2012 há uma preocupação em mostrar que hoje há inúmeros problemas de ordem ambiental e que esses devem ter destaque, uma vez que existe um subcapítulo apenas destinado a essa temática. Diferente disso, o livro do Período Militar apresenta essa questão de forma tímida e atrelada ao texto.

Tratando-se do discurso, não se pode deixar de considerar a explicita necessidade da autoafirmação nacional apresentada na análise dos livros didáticos do Período Militar. A exaltação exagerada acontece em todos os conteúdos como uma regra, mostrando a necessidade de mostrar como o Brasil um país bom, bonito em sua paisagem e disposto a tornar-se sempre melhor.

Contudo no livro de 2012, as considerações políticas são mais sutis, dando dicas de como é ou como poderia ser determinadas medidas. Nesta obra, em nenhum momento há um texto referindo-se a exaltação nacional ou indicação de que somos melhores ou piores que os outros países.

Assim, pode-se perceber que há diferenças e semelhanças entre os livros trabalhados. Desta forma, apesar das claras diferenças de discurso, os dois cumprem seu papel como fornecedor de conhecimento e recurso de auxílio ao professor em sala de aula. Sendo assim, não se percebeu nenhum erro conceitual em nas obras analisadas sugerindo que são indicadas para cumprir sua função.

Percebe-se assim que diversos aspectos influenciam no discurso apresentado nos livros didáticos: como se esperava a questão política está explícita mais no livro didático do Período Militar que o do atual, já as questões voltadas à preservação do meio ambiente é mais evidente nos livros atuais que no do ano 1968.

De tal modo pode-se notar que os temas da atualidade tendem a ser incorporado aos discursos didáticos para que os educandos tenham bases teóricas, para discutir acerca dos conteúdos cotidianos. Essa necessidade colabora com a difusão das mídias, que atendem a preferências pessoais e desenvolvem, muitas vezes, um discurso tendencioso a respeito de temas que precisam ser identificados e discutidos pelos educandos. 
Para finalizar, é possível afirmar que como sempre, o livro didático continua sendo uma mídia importantíssima para a manutenção básica das aulas tanto do ensino fundamental como média, além de ser um instrumento de apoio ao professor de qualquer disciplina. Seus textos precisam ser analisados e discutidos para que todos possam ter noção da realidade que os toca, e assim, independente do período histórico e do que se divulga neste tempo, desenvolver e preservar o criticidade dos educandos através da indagação do que se noticia em qualquer mídia é uma das inúmeras funções intrínseca a profissão de professor.

\section{BIBLIOGRAFIA}

ASSUNÇÃO, Cristina Adelina de. A ditadura militar retratada nos livros didáticos de História do Brasil de 1964 a 1885. 118p. Dissertação (Mestrado em História Social), Pontifícia Universidade Católica de São Paulo, São Paulo, 2009.

AZEVEDO, Aroldo de; Terra Brasileira. 42 ed. São Paulo: São Paulo Editora S. A. 1968. 106p.

BRASIL. Decreto-Lei № 1006, de 30 de dezembro de 1938. Presidência da República: câmara dos deputados, Brasília, DF, 30 de dezembro de 1938. Disponível em: < http://www2.camara.leg.br/legin/fed/declei/1930-1939/decreto-lei-1006-30-dezembro1938-350741-publicacaooriginal-1-pe.html >. Acesso em: 06 out. 2014.

BRASIL. Decreto-Lei no 8460, de 26 de dezembro de 1945. Presidência da República: câmara dos deputados, Brasília, DF, 26 de dezembro de 1945. Disponível em: < http://www2.camara.leg.br/legin/fed/declei/1940-1949/decreto-lei-8460-26-dezembro1945-416379-publicacaooriginal-1-pe.html >. Acesso em: 06 out. 2014.

BRASIL. Decreto no 77.107, de 04 de fevereiro de 1976. Presidência da República: câmara dos deputados, Brasília, DF, 04 de fevereiro de 1976. Disponível em: < http://www2.camara.leg.br/legin/fed/decret/1970-1979/decreto-77107-4-fevereiro-1976425615-publicacaooriginal-1-pe.html >. Acesso em: 06 out. 2013.

BRASIL. Decreto no 91.542, de 19 de outubro de 1985. Presidência da República: câmara dos deputados, Brasília, DF, 19 de outubro de 1985. Disponível em: < http://www2.camara.leg.br/legin/fed/decret/1980-1987/decreto-91542-19-agosto-1985441959-publicacaooriginal-1-pe.html >. Acesso em: 06 out. 2013.

FERREIRA JR, Amarilio; BITTAR Marisa. A ditadura militar e a proletarização dos professores. Disponível em: < www.scielo.br/pdf/es/v27n97/a05v2797.pdf >. Acesso em 08 out. 2014.

FREITAS, Neli Klix; RODRIGUES, Melissa Haag. O LIVRO DIDÁTICO AO LONGO DO TEMPO: a forma do conteúdo. DAPesquisa. v.3, n.1. Disponível em: < http://www.ceart.udesc.br/revista_dapesquisa/volume3/numero1/plasticas/melissaneli.pdf >. Acesso em 01 out. 2014.

FUNDO NACIONAL DE DESENVOLVIMENTO DA EDUCAÇÃO. Livro didático: Histórico. Disponível em: < http://www.fnde.gov.br/fnde/institucional/agenda-dopresidente/item/518-hist\%C3\%B3rico >. Acesso em: 06 out. 2014. 
KUNZLER, Edinho Carlos; WIZNIEWSKY, Carmen Rejane Flores. A ideologia nos livros didáticos de geografia durante o regime militar no Brasil. Terra Livre. v. 1, n. 28, p. 197 - 220, 2007. Disponível em: < http://www.agb.org.br/files/TL_N28.pdf >. Acesso em: 01 set. 2014.

MARTINS, Dadá; BIGOTTO, Francisco; VITIELLO, Márcio. Geografia: sociedade e cotidiano. 4. ed. São Paulo: Escala Educacional, 2012.

MARTINS, Rosa Elisabete Militz Wypyczynski. O livro didático no ensino da geografia. Portal

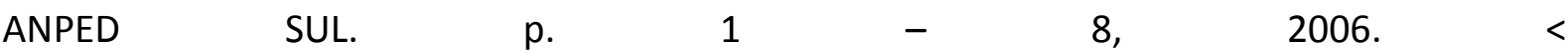
http://www.portalanpedsul.com.br/admin/uploads/2006/Curriculo_e_Saberes/Painel/07_3 2_42_PA252.pdf >. Acesso em: 01 set. 2014.

MÉDICI, Emílio Garrastazu. Tarefa de todos nós. Brasília, DF: Imprensa Nacional, 1971. 103p.

PINNA, Paula Priscila Gomes do Nascimento. A relação entre o ensino e o uso do livro didático de geografia. 104p. Dissertação (Mestrado em Geografia), Universidade Federal da Paraíba, Paraíba, 2009.

ROMANELLI, Otaíza de Oliveira. História da educação no Brasil: 1930/1973. 19. ed. Petrópolis: Editora Vozes, 1997.

SOARES, Jandson Bernardo; SOUZA Wendell de Oliveira. MEMORIAL DO PNLD: elaboração, natureza e funcionalidade. In: SEMANA DE HUMANIDADES, 19., 2011, Natal. Anais eletrônicos... Disponível em: < http://www.cchla.ufrn.br/shXIX/anais/GT23/ARTIGO\%20-.pdf >. Acesso em: 01 out. 2014.

VELOSO, Fernando A.; VILLELA, André; GIAMBIAGI. Determinantes do "milagre" econômico brasileiro (1968-1973): Uma análise Empírica. Disponível em: < http://www.scielo.br/pdf/rbe/v62n2/06.pdf >. Acesso em 08 out. 2014.

XAVIER, Erica da Silva. OS CRITÉRIOS DE AVALIAÇÃO PARA OS LIVROS DIDÁTICOS DE HISTÓRIA: A (des) caracterização da canção como fonte histórica. In: SIMPÓSIO NACIONAL DE HISTÓRIA, 27., 2013, Natal. Anais eletrônicos... Disponível em: < http://www.snh2013.anpuh.org/resources/anais/27/1364929459_ARQUIVO_ARTIGOANPU H-2013.pdf >. Acesso em: 01 out. 2014.

WIKIPÉDIA Enciclopédia Livre. Programa Nacional de Livro Didáticos. Disponível em < http://pt.wikipedia.org/wiki/Programa_Nacional_de_Livros_Did\%C3\%A1ticos >. Acesso em: 01 out. 2014.

WIKIPÉDIA Enciclopédia Livre. Regime Militar no Brasil. Disponível em: < http://pt.wikipedia.org/wiki/Regime_militar_no_Brasil >. Acesso em: 08 out. 2014.

\begin{tabular}{|r|r|}
$\begin{array}{r}\text { Artigo submetido em } \\
\text { Artigo aceito em }\end{array}$ 03/03/2015 \\
\hline
\end{tabular}

